\title{
Pd/Pt IMBALANCE IN LAVAS AND INTRUSIONS OF THE NORILSK-TALNAKH ORE REGION
}

\section{T.V. Dudkin ${ }^{1,2}$, A.E. Marfin $\oplus^{1 \bowtie}$, A.V. Ivanov $\oplus^{1}$, V.S. Kamenetsky $\oplus^{1}$}

${ }^{1}$ Institute of the Earth's Crust, Siberian Branch of the Russian Academy of Sciences, 128 Lermontov St, Irkutsk 664033, Russia

${ }^{2}$ Norilskgeologiya LLC, 1 Promzona, Norilsk, 663300, Russia

ABSTRACT. The paper considers the Pd/Pt ratio in the ores of the Norilsk- 1 and Talnakh deposits associated with the Permian-Triassic intrusions of the Norilsk type in comparison with that in the lavas of the same age in the Norilsk region. The Pd/Pt mean ratio is 1 in lavas and 2-4 times higher than that in ores and barren horizons of the Norilsk-1 and Talnakh intrusions. Such an increase implies that these elements were borrowed by magma from small and medium-sized crust deposits associated with the previous stage of Permian island-arc volcanism.

KEYWORDS: Noirilsk; Talnakh; copper-nickel deposit; Pd; Pt; basalts; PGE concentrations

FUNDING: The work is done in the Center for Geodynamics and Geochronology with the support from RFBR as part of the scientific research project 19-35-90013.

\section{SHORT COMMUNICATION}

Correspondence: Alexander E. Marfin, marfin1309@gmail.com
Received: November 26, 2020

Revised: August 10, 2021

Accepted: August 12. 2021

FOR CITATION: Dudkin T.V., Marfin A.E., Ivanov A.V., Kamenetsky V.S., 2021. Pd/Pt imbalance in lavas and intrusions of the NorilskTalnakh ore region. Geodynamics \& Tectonophysics 12 (4), 883-890. doi:10.5800/GT-2021-12-4-0560 


\title{
ДИСБАЛАНС Рd/Рt В ЛАВАХ И ИНТРУЗИЯХ НОРИЛЬСКО-ТАЛНАХСКОГО РУДНОГО РАЙОНА
}

\author{
Т.В. Дудкин ${ }^{1,2}$, А.Е. Марфин ${ }^{1}$, А.В. Иванов ${ }^{1}$, В.С. Каменецкий ${ }^{1}$
}

${ }^{1}$ Институт земной коры СО РАН, 664033, Иркутск, ул. Лермонтова, 128, Россия

${ }^{2} 000$ «Норильскгеология», 663300, Норильск, Промзона, 1, Россия

АНнотАЦИЯ. В работе рассмотрены значения Pd/Pt отношения в рудах месторождений Норильск-1 и Талнахское, связанных с пермско-триасовыми интрузиями норильского типа, а также проведено сравнение с таковым отношением в одновозрастных лавах Норильского района. Показано, что в лавах Pd/Pt otношение составляет в среднем 1, а в рудах и безрудных горизонтах интрузий Норильск-1 и Талнах превышает это значение в 2-4 раза. Наиболее вероятно, такое увеличение указывает на заимствование магмой этих элементов из существовавших в коре малых и средних месторождений, связанных с предшествующим этапом пермского островодужного вулканизма.

КЛЮчЕВЫЕ СЛоВА: Норильск; Талнах; медно-никелевое месторождение; Pd; Pt; базальты; концентрации ЭПГ

ФИНАНСИРОВАНИЕ: Работа выполнена в ЦКП «Геодинамика и геохронология» при поддержке РФФИ в рамках научного проекта № 19-35-90013.

\section{1. ВВЕДЕНИЕ}

Месторождение Норильск-1, связанное с одноименной интрузией, известно с 1920-х годов [Rozhkov, 1933; Godlevsky, 1959; Urvantsev, 1923, 1927]. Открытие Талнахского и Октябрьского месторождений, приуроченное к Талнахской и Хараелахской интрузиям, приходится на 1960-е годы [Egorov, Sukhanova, 1963]. В настоящий момент идет разведка флангов этих месторождений, осуществляются поиски месторождений, связанных с другими интрузиями. В результате этих работ установлено, что из всего набора присутствующих на месторождениях элементов платиновой группы (ЭПГ) наибольшие содержания имеет Pd, за ним следует Pt, а остальные элементы ЭПГ находятся в заметно меньших концентрациях. Такое распределение ЭПГ является типичной характеристикой медно-никелевых месторождений, связанных с трапповым магматизмом [Naldrett, 2004]. В то же время эффузивные траппы, для которых, как считается, интрузии, в том числе содержащие медно-никелевые месторождения, являются подводящими каналами [Latyshev et al., 2020], имеют схожие концентрации Pd и Pt [Ivanov, 2007]. Несмотря на долгую историю изучения лав и интрузий в Норильск-Талнахском районе, на этот факт не обращали внимания. Известно также, что различные типы руд разных месторождений характеризуются широким разбросом значений $\mathrm{Pd} / \mathrm{Pt}$ отношений - от 0.6 до 12.0 для различных месторождений [Naldrett, 2004; Krivolutskaya, 2016; Tolstykh et al., 2020] со средним значением, равным 3 [Naldrett, 2004]. Однако при этом либо не приводится количество анализов для осреднения, по которым рассчитаны эти значения, либо не дается описание типов пород [Naldrett, 2004; Krivolutskaya, 2016]. Таким образом, остается непонятным, является ли разброс Pd/Pt отношений случайным артефактом или отражает какую-то закономерность. Цель этой работы - во-первых, рассчитать минимальный набор стандартных статистических параметров (максимальное, минимальное, среднее и медианное значение) для $\mathrm{Pd} / \mathrm{Pt}$ отношения в рудных и безрудных интервалах интрузий Норильск-1 и Талнахская, основываясь на большом количестве анализов; во-вторых, обсудить причину вариаций этого отношения, чему ранее не уделялось достаточного внимания.

\section{2. ГЕОЛОГИЧЕСКОЕ СТРОЕНИЕ МЕСТОРОЖДЕНИЙ}

Месторождения Норильско-Талнахского района локализуются на северо-западе Сибирской платформы и связаны с дифференцированными трапповыми интрузивами (рис. 1, а). Характеристика трапповых свит региона, а также пород интрузивов и связанных с ними руд подробно представлена в многочисленных публикациях отечественных и зарубежных авторов [Zolotukhin et al., 1975; Turovtsev, 2002; Ryabov et al., 2000; Naldrett, 1992; Walker et al., 1994; Wooden et al., 1992].

В районе выделяются минерализованные, слабоминерализованные и безрудные интрузивы. Первые относятся к «норильскому» типу интрузий. В пределах интрузии Норильск-1, являющейся предметом этого исследования, располагаются месторождения Норильск-1 и Масловское. Месторождение Норильск-1 отрабатывается рудником «Заполярный», включающим в себя открытую и подземную разработку. В эту работу включены новые материалы по скважинам, пройденным с дневной поверхности и с подземных горных выработок. По типу руд в контуре месторождения Норильск-1 отмечаются малосульфидные в кровле интрузива и вкрапленные ближе к его подошве. Изредка встречаются маломощные прослои массивных, густовкрапленных, прожилково-вкрапленных руд, расположенных у нижнего экзоконтакта интрузии с титан-авгитовыми базальтами ивакинской свиты. Среди месторождений Талнахского рудного узла мы приводим данные по скважинам, пройденным с дневной поверхности, так как 


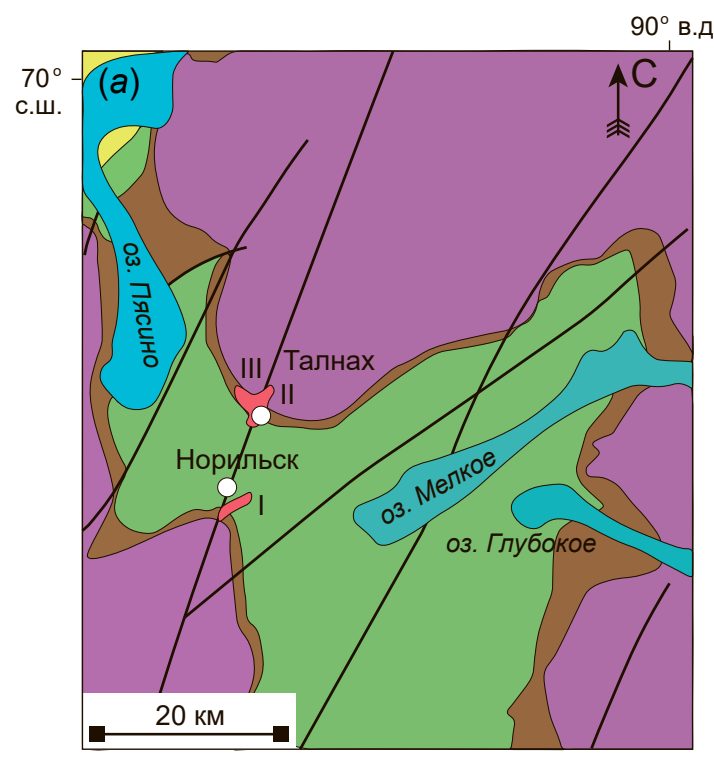

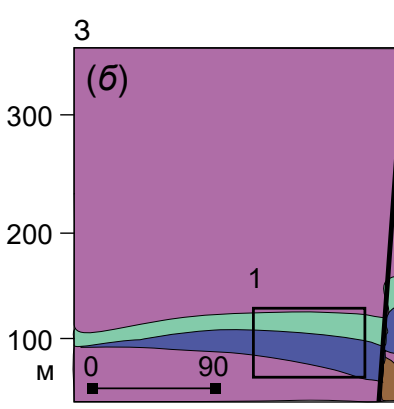

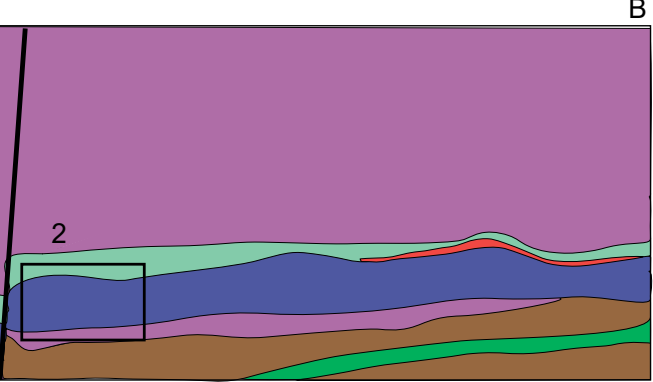

3
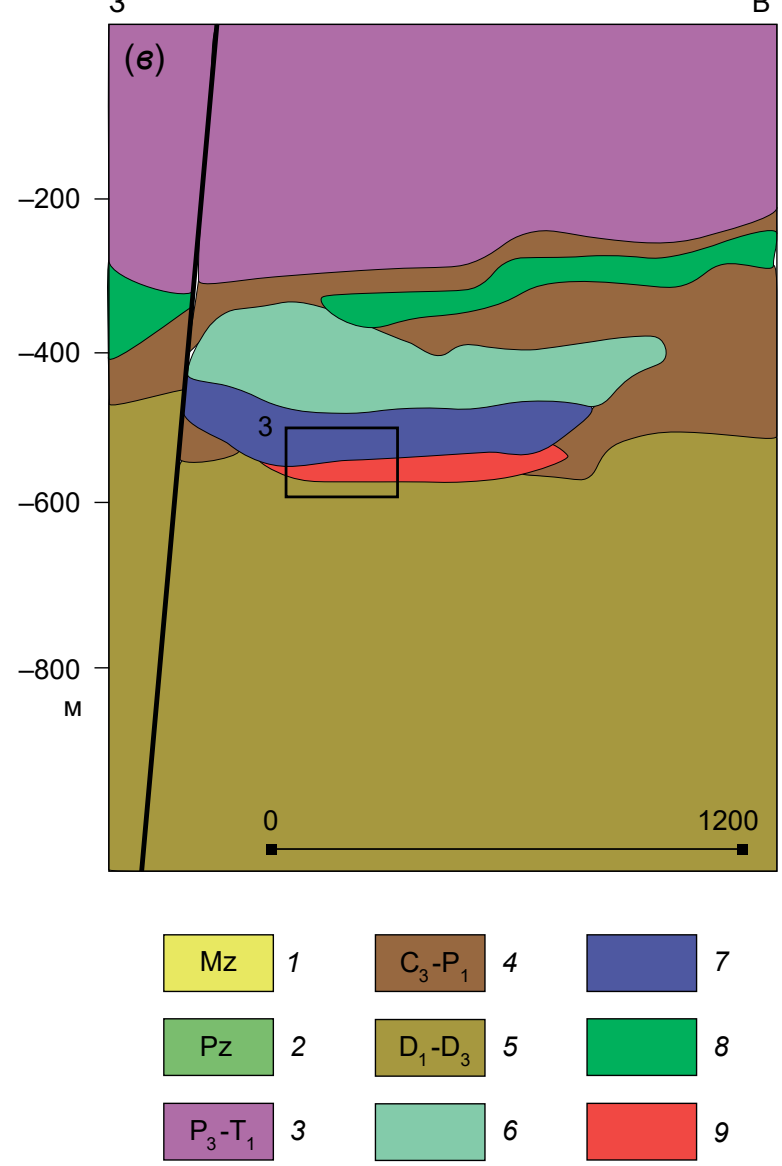

Рис. 1. Геологическая карта и разрезы интрузий региона.

(a) - схематическая геологическая карта Норильско-Талнахского региона; $(б$, в) - разрезы месторождений: (б) - Норильск-1 [Sluzhenikin et al., 2016], (в) - Талнахское [Duzhikov, Distler, 1988]. I - месторождение Норильск-1, II - Талнахское месторождение, III - Октябрьское месторождение (по [Sluzhenikin et al., 2014], с упрощениями); 1, 2, 3 - детальные разрезы участков месторождений Норильск-1 $(1,2)$ и Талнахское $(3)$ с нанесенными стволами скважин эксплуатационной разведки (вдоль ствола скважины нанесены изменения Pd/Pt отношения).

1 - мезозойские отложения; 2 - палеозойские отложения; 3 - пермско-триасовые вулканические породы; 4 - угленосные терригенные отложения; 5 - ангидритсодержащие девонские породы; 6 - породы верхнего эндоконтакта; 7 - пикритовые, такситовые габбро-долериты; 8 - дайки и силлы; 9 - массивные руды.

Fig. 1. Geological map and sections of intrusions of the region.

(a) - schematic geological map of the Norilsk-Talnakh region; $(б, 8)$ - cross-sections of the deposits: (б) - Norilsk-1 [Sluzhenikin et al., 2016], (в) - Talnakh [Duzhikov, Distler, 1988]. I - Norilsk-1 deposit, II - Talnakh deposit, III - Oktyabrsky deposit (after [Sluzhenikin et al., 2014] with some simplifications); 1, 2, 3 - detailed cross-sections of the Norilsk-1 (1, 2) and Talnakh (3) deposits with the exploration boreholes placed thereon (changes in the Pt/Pd ratio are plotted along the borehole).

1 - Mesozoic sediments; 2 - Paleozoic sediments; 3 - Permian-Triassic volcanic rocks; 4 - Carboniferous terrigenous sediments; 5 - anhydrite-bearing Devonian rocks; 6 - rocks of the upper endocontact; 7 - picrite, taxite gabbrodolerites; 8 - dikes and sills; 9 massive ores. 
ввиду глубокого расположения рудного тела они отрабатываются подземным способом.

Интрузии «норильского» типа представлены вытянутыми телами неправильной формы, называемыми хонолитами, протяженностью до 12 км, шириной 24 км при мощности от 20 до 350 м. Рудоносные интрузии имеют однотипную последовательность расслоенных серий пород [Krivolutskaya, 2011].

Основными типами руд на месторождениях являются вкрапленные в такситовых и пикритовых габбродолеритах («вкрапленные» руды), залегающие ближе к нижней части интрузий, и массивные («богатые» руды), залегающие в основании пород расслоенной серии (рис. 1, б) и часто в экзоконтакте. На Талнахском месторождении встречаются также прожилково-вкрапленные руды, расположенные в верхних эндо- и экзоконтактах в метаморфизованных и метасоматически измененных породах рамы (пироксеновые роговики, скарны и т.д.) [Turovtsev, 2002]. Перспективным источником ЭПГ считается горизонт малосульфидного оруденения в рудоносных интрузивах норильского региона, приуроченный к породам верхнего эндоконтакта [Sluzhenikin et al., 2016]. Малосульфидное оруденение характеризуется низкими значениями $\mathrm{Cu}$ и $\mathrm{Ni}(0.2-0.4$ \%), при этом концентрация ЭПГ может достигать 20-40 г/т. Малосульфидные руды сложены пестрыми петрографическими разностями пород: эруптивными брекчиями, гибридно-метасоматическими породами, контактовыми габбро-долеритами, габбро-диоритами, лейкократовыми габбро, хромитоносными такситовыми габбро.

Концентрация ЭПГ в массивных и вкрапленных рудах связана с собственными минеральными фазами и изоморфным вхождением в состав сульфидных фаз. Для вкрапленных руд Талнаха 90-95 \% Pt ассоциируется со сперрилитом, для Норильска-1 - со сплавами Pt-Fe (в основном изоферроплатина и тетраферроплатина) [Sluzhenikin, 2011]. Значимое количество Pd изоморфно входит в состав пентландита, где его концентрации составляют сотни г/т с отдельными анализами в первые тысячи г/т [Mansur et al., 2019], или Pd представлен (a)

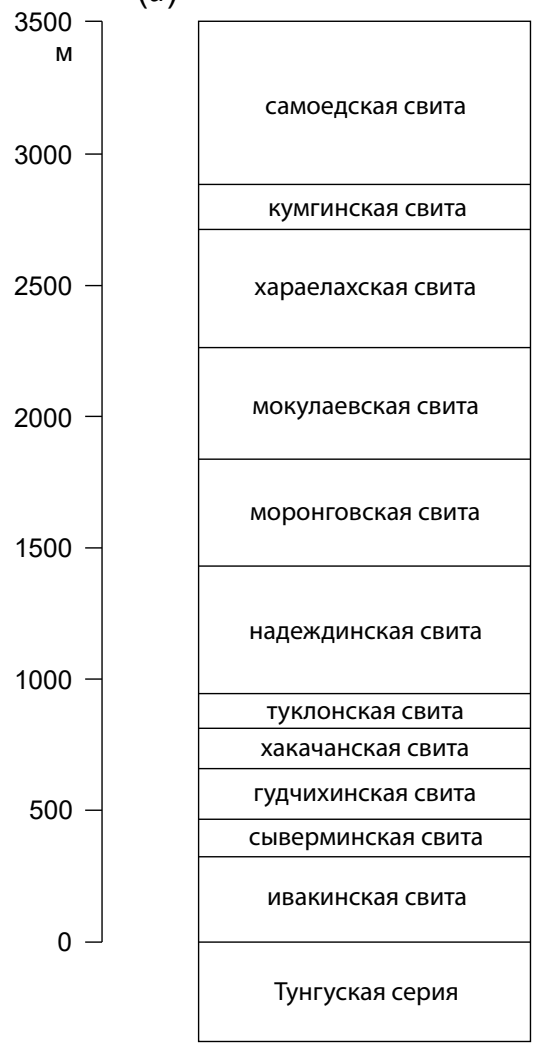

(б) 0

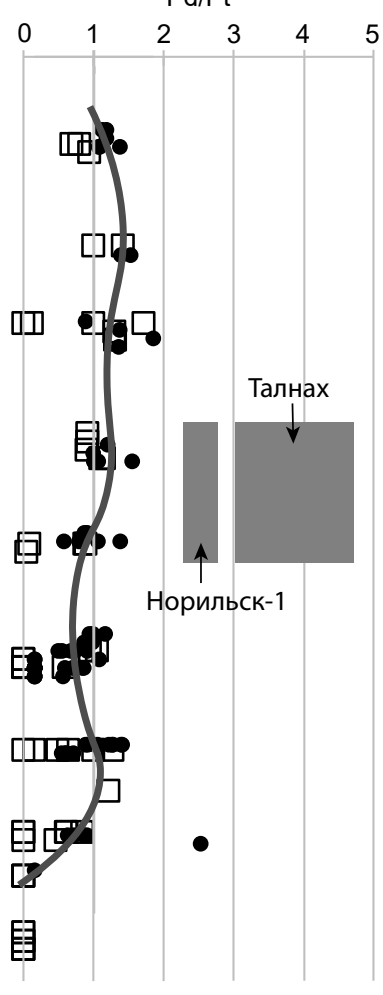

Рис. 2. Сводный разрез осадочной (Тунгусская серия) и вулканогенной (ивакинская - самоедская свиты) толщи НорильскоТалнахского рудного района и палеомагнитная характеристика базальтов и осадков по данным [Latyshev et al., 2020] (a); Pd/Pt отношения в базальтах (б): круги - [Lightfoot, Keays, 2005] и квадраты - [Wooden et al., 1993].

Сплошная извилистая линия - средние значения Pd/Pt в лавах. Серыми полями показаны диапазоны отношений в различных типах руд и вмещающих пород интрузий Норильск-1 и Талнахская (эта работа).

Fig. 2. A composite section of sedimentary (Tunguska Series) and volcanogenic (Ivakino - Samoyed formations) strata of the NorilskTalnakh ore region and paleomagnetic characteristics of basalts and sediments according to [Latyshev et al., 2020] (a); Pd/Pt ratios in basalts (б): circles - [Lightfoot, Keays, 2005] and squares - [Wooden et al., 1993].

The solid curve is the Pd/Pt mean ratios in lavas. The gray fields show the ranges of ratios in different types of ores and host rocks of the Norilsk-1 and Talnakh deposits (presented herein). 
новообразованными минералами, замещающими пентландит [Spiridonov et al., 2015]. В свою очередь, Os, Re, $\mathrm{Ir}, \mathrm{Rh}$ концентрируются в пирротине и пентландите [Barnes et al., 2006; Mansur et al., 2019].

В результате систематического изучения пород рудоносных интрузивов были установлены временные ограничения на время их внедрения, основанные на палеомагнитных и U-Pb геохронологических данных (рис. 2). Согласно полученным палеомагнитным данным, внедрение рудоносных интрузивов происходило на границе моронговской и мокулаевской свит [Latyshev et al., 2020] около 252 млн лет назад [Burgess, Bowring, 2015].

\section{3. МЕТОДЫ}

Нами были изучены Pd/Pt отношения в массивных рудах, во вкрапленных рудах такситовых и пикритовых габбро-долеритов, а также в породах, называемых здесь «безрудными», т.е. находящихся вне контура рудных тел и представленных преимущественно оливиновыми габбро-долеритами. Опробованы месторождения Норильск-1 в его северной части в пределах рудника «Заполярный» и Талнахское - в пределах рудника «Таймырский». Каменный материал взят из скважин, пробуренных с дневной поверхности и с подземных горных выработок. Опробование керна осуществлялось интервалами от 0.3 до 3.0 м, в зависимости от концентрации рудного компонента (чаще при видимом содержании сульфида). Всего использовано 310 образцов. Анализ концентраций Pt и Pd в них выполнен в контрольно-аналитическом управлении ЗФ ПАО «ГМК Норильский никель» методами атомно-эмиссионной спектрометрии и масс-спектрометрии с индуктивно связанной плазмой после концентрирования в никелевый штейн. Навеску пробы штейна растворяют в соляной кислоте, при этом сульфиды $\mathrm{Ni}$ и частично сульфиды $\mathrm{Cu}$ и Ag образуют растворимые хлориды. Сульфиды при этом остаются в нерастворимом остатке (НО). Раствор фильтруют через тигель Шотта или Гуча. Фильтрат отбрасывают, НО растворяют в соляной кислоте с добавлением азотной кислоты или пероксида водорода. $\mathrm{B}$ растворе измеряют концентрации $\mathrm{Pt}$ и $\mathrm{Pd}$ методами АЭС-ИСП и/или МС-ИСП.

\section{4. РЕЗУЛЬТАТЫ}

По полученным аналитическим данным рассчитаны Pd/Pt отношения, которые сгруппированы по месторождениям Норильск-1 и Талнахское, а в пределах этих месторождений - по типу руд (вкрапленная, массивная), по породам, находящимся за контуром рудного тела, определяемым экономической целесообразностью добычи, а также по типу скважин, пройденных с поверхности или с подземных выработок. Последнее сделано по причине того, что поверхностные скважины бурились и анализировались в прошлом веке, а данные по подземным скважинам получены за последние 3-5 лет, т.е. чтобы исключить возможные аналитические несогласования. В табл. 1 для Pd/Pt отношений приведены максимальные и минимальные значения, средние значения со стандартным отклонением и медиана. Известно, что медиана менее чувствительна к выбросам в сравнении со средним значением. Значение медианы Pd/Pt отношений для вкрапленной руды месторождения Норильск-1 составляет 2.5, для малосульфидной руды - 2.2, для «безрудных» оливиновых габбро-долеритов - 2.5. При этом все значения перекрываются в пределах стандартных отклонений (табл. 1). Для Талнахского месторождения самые высокие значения

Таблица 1. Соотношение Pd/Pt в породах интрузий Норильск-1 и Талнах и их руд (данная работа) и в лавах толеитовых базальтов и пикритов Норильско-Талнахского региона [Lightfoot, Keays, 2005; Wooden et al., 1993]

Table 1. Pd/Pt ratios in Norilsk-1 and Talnakh deposits (presented herein) and in lavas of the Norilsk-Talknakh region [Lightfoot, Keays, 2005; Wooden et al., 1993]

\begin{tabular}{|c|c|c|c|c|c|c|c|c|}
\hline \multirow{2}{*}{ Интрузия } & \multirow{2}{*}{ Тип руд } & \multirow{2}{*}{$\begin{array}{c}\text { Положение } \\
\text { скважины }\end{array}$} & \multirow{2}{*}{$\begin{array}{c}\text { Кол-во } \\
\text { анализов }\end{array}$} & \multirow{2}{*}{$\bar{x}$} & \multirow{2}{*}{ md } & \multirow{2}{*}{$\sigma$} & \multicolumn{2}{|c|}{ г/т, мин.-макс. } \\
\hline & & & & & & & $\mathrm{Pd}$ & $\mathrm{Pt}$ \\
\hline \multicolumn{9}{|c|}{ Новые данные } \\
\hline \multirow{5}{*}{ Норильск-1 } & Вкрапленная руда & Поверхностные & 54 & 2.50 & 2.50 & 2.20 & $1.38-83.00$ & $0.54-14.30$ \\
\hline & Вкрапленная руда & Подземные & 66 & 2.60 & 2.50 & 0.40 & $1.70-20.00$ & $0.60-7.90$ \\
\hline & «Малосульфидная» руда & Подземные & 16 & 2.20 & 2.20 & 0.20 & $2.56-8.50$ & $1.14-4.06$ \\
\hline & Безрудные породы & Поверхностные & 42 & 2.30 & 2.50 & 0.80 & $0.20-2.75$ & $0.20-1.40$ \\
\hline & \multicolumn{2}{|c|}{ Общее для месторождения } & 178 & 2.60 & 2.53 & 1.30 & $0.20-83.00$ & $0.20-14.30$ \\
\hline \multirow{4}{*}{ Талнахская } & Массивная руда & & 33 & 4.70 & 4.10 & 1.40 & $1.61-27.00$ & $0.40-4.90$ \\
\hline & Вкрапленная руда & Поверхностные & 71 & 3.80 & 3.80 & 1.00 & $0.24-14.00$ & $0.20-4.07$ \\
\hline & Безрудные породы & & 28 & 3.10 & 3.20 & 0.90 & $0.37-2.20$ & $0.20-0.55$ \\
\hline & \multicolumn{2}{|c|}{ Общее для месторождения } & 132 & 3.87 & 3.83 & 1.21 & $0.24-27.00$ & $0.20-4.90$ \\
\hline Базальты & Все свиты & & 93 & 1.00 & 0.90 & 0.70 & $<0.02$ & $<0.012$ \\
\hline
\end{tabular}

Примечание. $\bar{x}$ - среднеарифметическое; md - медиана; $\sigma$ - стандартное отклонение.

Note. $\bar{x}$ - arithmetic mean; md - median; $\sigma$-standard deviation. 
медианы Pd/Pt фиксируются в массивной руде - 4.1, во вкрапленной руде значение медианы составляет 3.8 , а для безрудных интрузивных пород - 3.2 (табл. 1). Эти значения находятся в пределах стандартных отклонений. Как видно из приведенных данных, высокое $\mathrm{Pd} / \mathrm{Pt}$ отношение, во-первых, фиксируется не только в рудах (вкрапленных и массивных), но и в «безрудных» породах, а, во-вторых, в пределах одного месторождения отсутствуют статистически значимые вариации.

\section{5. ОБСУЖДЕНИЕ}

Полученные значения Pd/Pt отношений в целом согласуются с опубликованными ранее [Naldrett, 2004; Tolstykh et al., 2020], но имеются некоторые различия. В общем виде, исходя из данных [Naldrett, 2004], возникает ощущение, что Pd/Pt отношение на каждом месторождении растет от вкрапленных руд к массивным. Так, для вкрапленных и массивных руд месторождения Норильск-1 приводятся значения 1.7 и 2.6 соответственно [Naldrett, 2004]. В нашей работе массивные руды не попали в выборку по причине их редкости на месторождении Норильск-1. Однако значения для двух типов руд (вкрапленной и малосульфидной) и для безрудных пород близки к значению, приведенному в работе [Naldrett, 2004] для массивной руды, и выше такового для вкрапленной. Скорее всего, относительно низкое значение для последней является локальным выбросом и не характеризует этот тип руды в целом ввиду ограниченности выборки. На разрезах на рис. 1 видно, что такие локальные выбросы встречаются вдоль скважин по разрезам. Аналогично для Талнахского месторождения в работе [Naldrett, 2004] приводятся значения 3.1 и 4.0 для вкрапленной и массивной руды соответственно. По нашим данным, в массивной руде Талнахского месторождения среднее и медианное значения тоже выше, чем во вкрапленной. Однако они перекрываются в рамках стандартных отклонений, т.е. можно говорить, что в пределах одного месторождения вариации $\mathrm{Pd} / \mathrm{Pt}$ достаточно стабильны. При этом $\mathrm{Pd} / \mathrm{Pt}$ отношения в целом для Талнахского месторождения выше такового для месторождения Норильск-1 и в обоих месторождениях выше, чем в одновозрастных лавах (рис. 2).

Рассмотрим возможную причину фракционирования значений Pd/Pt отношений. Так, медистые (прожилково-вкрапленные) руды Октябрьского месторождения, находящиеся в верхнем экзоконтакте Хараелахской интрузии и связанные, по-видимому, с процессами метаморфизма и метасоматоза [Turovtsev, 2002], характеризуются, по данным [Naldrett, 2004], Pd/Pt=10.4 при значениях этого отношения для вкрапленных и массивных руд этого же месторождения 3.7 и 4.5 соответственно (в данном случае различие между вторичными прожилково-вкрапленными и первичными вкрапленными рудами можно считать значимым), т.е. процесс вторичной модификации руды приводит к росту $\mathrm{Pd} / \mathrm{Pt}$ отношений. Однако вряд ли можно объяснить увеличение Pd/Pt отношений от месторождения Норильск-1 к Талнахскому в одном и том же первичном типе, например вкрапленных руд, метаморфическими и метасоматическими процессами.

Как было сказано выше, пентландит характеризуется высокими концентрациями Рd при низких концентрациях Pt. Следовательно, дифференциация руды по этому минералу могла бы приводить к вариациям $\mathrm{Pd} / \mathrm{Pt}$ отношения. Наиболее полные аналитические данные по ЭПГ на сегодняшний день приводятся в работе [Tolstykh et al., 2020] по ряду скважин южной части месторождения Норильск-1. В этой работе обнаружена обратная корреляция $\mathrm{Pd} / \mathrm{Pt}$ и $\mathrm{Ni} / \mathrm{Cu}$ отношений, т.е. тренд обратный - руды с большим содержанием пентландита имеют ниже Pd/Pt отношения.

Наконец, Pd и Pt могут заимствоваться из коровых пород, в которых изначальное $\mathrm{Pd} / \mathrm{Pt}>1$, а не из мантийных расплавов, у которых это отношение близко к 1 . На наш взгляд, эта версия лучше всего согласуется с наблюдениями.

В перидотитовой мантии Pt и Pd находятся в сульфидных включениях в интерстициях между силикатными минералами. Поскольку коэффициент распределения сульфид - расплав для этих элементов очень большой (>103 [Bézos et al., 2005]), эти элементы будут полностью оставаться в источнике до тех пор, пока сульфид не перейдет полностью в расплав. Таким образом, обогащение расплава $\mathrm{Pt}$ и $\mathrm{Pd}$ должно происходить резко и, возможно, не зависеть от степени частичного плавления. Так, базальты островных дуг и внутриплитных океанических островов, характеризующиеся высокими и низкими степенями частичного плавления, соответственно могут быть обогащены этими элементами на уровне от единиц до первых десятков мг/т [Ivanov et al., 2008]. Базальты срединно-океанических хребтов и щелочные континентальные базальты, характеризующиеся также высокими и низкими степенями частичного плавления, наоборот, обеднены этими элементами (<1 мг/т [Ivanov et al., 2008; Ivanov, Litasov, 2014]). Базальты высокотитанистой и низкотитанистых серий сибирских траппов характеризуются низкими (ниже предела обнаружения метода нейтронной активации) и высокими ( 10 мг/т) концентрациями этих элементов [Lightfoot, Keays, 2005; Wooden et al., 1993]. Концентрации Pt и Pd в первичном мантийном расплаве, скорее всего, просто отражают наличие или отсутствие этих элементов в источнике. Так, их высокие концентрации в островодужных породах связываются с обогащением мантийного клина этими элементами при дегазации слэба [Kepezhinskas et al., 2002; McInnes et al., 1999]. Высокотитанистые базальты сибирских траппов с низкими концентрациями Pt и Pd, по-видимому, образовывались при плавлении мафического источника, т.е. рециклированных базальтов типа MORB [Ivanov, 2007; Sobolev et al., 2009]. По возрасту Норильск-Талнахские рудоносные интрузии соответствуют обогащенным Pt и Pd (на уровне 10 мг/т) низкотитанистым базальтам моронговской и мокулаевской свит, мантийным 
субстратом которых, по-видимому, служили перидотиты [Ivanov, 2007; Sobolev et al., 2009]. В работе [Czamanske et al., 2000] обнаружено, что под базальтовой толщей в Норильск-Талнахском районе имеются пермские островодужные вулканиты. В них неизвестны Pd/Pt отношения, но, например, островодужные породы в целом по миру характеризуются $\mathrm{Pd} / \mathrm{Pt}$ отношениями 1.9 с локальными вариациями от 1 до 20 [Ivanov et al., 2008; McInnes et al., 1999; Woodland et al., 2002], т.e. источником платины и палладия в Норильских месторождениях могли быть коровые породы, возможно, древние месторождения и рудопроявления, о чем писали, в частности, в ряде работ [Rogover, 1959; Starostin, Sorohtin, 2011; Krivolutskaya, 2011].

\section{6. ЗАКЛЮЧЕНИЕ}

Анализ Pd/Pt отношений на большой выборке образцов подтвердил, что руды, связанные с интрузиями норильского типа, имеют значения выше единицы, характерные для одновозрастных лав. При этом $\mathrm{Pd} / \mathrm{Pt}$ отношения в рудах разных типов одного и того же месторождения не отличаются, а отличается между разными месторождениями. Из возможных причин увеличения $\mathrm{Pd} / \mathrm{Pt}$ отношений в рудных интрузиях, по сравнению с одновозрастными лавами, наиболее вероятной представляется ассимиляция магмой ЭПГ из серии гипотетических мелких и средних месторождений, уже существовавших в коре, образовавшихся в связи с предшествующим этапом пермского островодужного вулканизма.

\section{7. ЛИТЕРАТУРА / REFERENCES}

Barnes S.-J., Cox R.A., Zientek M.L., 2006. Platinum-Group Element, Gold, Silver and Base Metal Distribution in Compositionally Zoned Sulfide Droplets from the Medvezky Creek Mine, Noril'sk, Russia. Contributions to Mineralogy and Petrology 152, 187-200. https://doi.org/10.1007/s00410006-0100-9.

Bézos A., Lorand J.P., Humler E., Gros M., 2005. PlatinumGroup Element Systematics in Mid-Oceanic Ridge Basaltic Glasses from the Pacific, Atlantic, and Indian Oceans. Geochimica et Cosmochimica Acta 69 (10), 2613-2627. https:// doi.org/10.1016/j.gca.2004.10.023.

Burgess S.D., Bowring S.A., 2015. High-Precision Geochronology Confirms Voluminous Magmatism before, during, and after Earth's Most Severe Extinction. Science Advances 1 (7). https://doi.org/10.1126/sciadv.1500470.

Czamanske G.K., Wooden J.L., Walker R.J., Fedorenko V.A., Simonov O.N., Budahn J.R., Siems D.F., 2000. Geochemical, Isotopic, and SHRIMP Age Data for Precambrian Basement Rocks, Permian Volcanic Rocks, and Sedimentary Host Rocks to the Ore-Bearing Intrusions, Noril'sk-Talnakh District, Siberian Russia. International Geology Review 42 (10), 895927. https://doi.org/10.1080/00206810009465117.

Duzhikov O.A., Distler V.V. (Eds), 1988. Geology and Mineralogy of Sulfide Deposits, Noril'sk Region, USSR. Special Publications of the Society of Economic Geologists 1, 242 p. https://doi.org/10.5382/SP.01.
Egorov V.N., Sukhanova E.N., 1963. Talnakh Ore-Bearing Intrusion in the Northwest of the Siberian Platform. Prospect and Protection of Mineral Resources 1, 17-21 (in Russian) [Егоров В.Н., Суханова Е.Н. Талнахский рудоносный интрузив на северо-западе Сибирской платформы // Разведка и охрана недр. 1963. № 1. С. 17-21].

Godlevsky M.N., 1959. Trap-Rocks and Ore-Bearing Intrusions of the Norilsk Region. Gosgeoltekhizdat, Moscow, 61 p. (in Russian) [Годлевский М.Н. Траппы и рудоносные интрузии Норильского района. М.: Госгеолтехиздат, 1959. 62 c.].

Ivanov A.V., 2007. Evaluation of Different Models for the Origin of the Siberian Traps. In: G.R. Foulger, D.M. Jurdy (Eds), Plates, Plumes and Planetary Processes. Geological Society of America Special Paper 430, 635-668. https: // doi.org/10.1130/2007.2430(31).

Ivanov A.V., Litasov K.D., 2014. The Deep Water Cycle and Flood Basalt Volcanism. International Geology Review 56 (1), 1-14. https://doi.org/10.1080/00206814.2013.817567.

Ivanov A.V., Perepelov A.B., Palesskii S.V., Nikolaeva I.V., 2008. First Data on the Distribution of Platinum Group Elements (Ir, Os, Ru, Pt, and Pd) and Re in Island-Arc Basalts of Kamchatka. Doklady Earth Sciences 420, 597. https:// doi.org/10.1134/S1028334X08040168.

Kepezhinskas P., Defant M. J., Widom E., 2002. Abundance and Distribution of PGE and $\mathrm{Au}$ in the Island-Arc Mantle: Implications for Sub-Arc Metasomatism. Lithos 60 (3-4), 113-128. https://doi.org/10.1016/S0024-4937(01) 00073-1.

Krivolutskaya N.A., 2011. Formation of PGM-Cu-Ni Deposits in the Process of Evolution of Flood-Basalt Magmatism in the Noril'sk Region. Geology of Ore Deposits 53 (4), 309-339. https://doi.org/10.1134/S1075701511040039.

Krivolutskaya N.A., 2016. Siberian Traps and Pt-Cu-Ni Deposits in the Noril'sk Area. Springer, p. 377. https://doi. org/10.1007/978-3-319-17205-7.

Latyshev A., Rad'ko V., Veselovskiy R., Fetisova A., Pavlov V., 2020. Correlation of the Permian-Triassic Ore-Bearing Intrusions of the Norilsk Region with the Volcanic Sequence of the Siberian Traps Based on the Paleomagnetic Data. Economic Geology 115 (6), 1227-1243. https://doi.org/ 10.5382/econgeo.4746.

Lightfoot P.C., Keays R.R., 2005. Siderophile and Chalcophile Metal Variations in Flood Basalts from the Siberian Trap, Noril'sk Region: Implications for the Origin of the NiCu-PGE Sulfide Ores. Economic Geology 100 (3), 439-462. https://doi.org/10.2113/gsecongeo.100.3.439.

Mansur E.T., Barnes S.J., Duran C.J., 2019. Textural and Compositional Evidence for the Formation of Pentlandite via Peritectic Reaction: Implications for the Distribution of Highly Siderophile Elements. Geology 47 (4), 351-354. https://doi.org/10.1130/G45779.1.

McInnes B.I., McBride J.S., Evans N.J., Lambert D.D., Andrew A.S., 1999. Osmium Isotope Constraints on Ore Metal Recycling in Subduction Zones. Science 286 (5439), 512516. https://doi.org/10.1126/science.286.5439.512.

Naldrett A.J., 1992. A Model for the Ni-Cu-PGE Ores of the Noril'sk Region and Its Application to Other Areas of 
Flood Basalt. Economic Geology 87 (8), 1945-1962. https:// doi.org/10.2113/gsecongeo.87.8.1945.

Naldrett A.J., 2004. Magmatic Sulfide Deposits: Geology, Geochemistry and Exploration. Springer-Verlag, Berlin Heidelberg, 727p. https://doi.org/10.1007/978-3-662-0 8444-1.

Rogover G.B., 1959. Norilsk-1 Deposit. Gosgeoltekhizdat, Moscow, 168 p. (in Russian) [Роговер Г.Б. Месторождение Норильск-1. М.: Госгеолтехиздат, 1959. 168 с.].

Rozhkov B.N., 1933. Materials on Metal Content of the Siberian Traps. Proceedings of the East Siberia Geology Trust 3, 248 p. (in Russian) [Рожков Б.Н. Материалы по металлоносности сибирских траппов. Труды Восточно-Сибирского геологоразведочного треста. 1933. Т. 3. 248 с.].

Ryabov V.V., Shevko A.Ya., Gora M.P., 2000. Magmatic Formations of the Norilsk Region. Vol. 1. Trap Petrology. Nonparel, Novosibirsk, 408 p. (in Russian) [Рябов В.В., Шевко А.Я., Гора М.П. Магматические образования Норильского района. Т. 1. Петрология траппов. Новосибирск: Нонпарель, 2000. 408 с.].

Sluzhenikin S.F., 2011. Platinum-Copper-Nickel and Platinum Ores of Norilsk Region and Their Ore Mineralization. Russian Journal of General Chemistry 81, 1288-1301. https:// doi.org/10.1134/S1070363211060351.

Sluzhenikin S.F., Distler V.V., Grigoryeva A.V., 2016. LowSulfide Platinum Ores of Norilsk Area - Promising Sources of Precious-Metals. Arctic Ecology and Economy 4, 32-45 (in Russian) [Служеникин С.Ф., Дистлер В.В., Григорьева А.В. Малосульфидные платиновые руды Норильского района - перспективные источники благородных металлов // Арктика: экология и экономика. 2016. № 4. C. 32-45].

Sluzhenikin S., Krivolutskaya N., Rad'ko V., Malitch K., Distler V., Fedorenko V., 2014. Ultramafic-Mafic Intrusions, Volcanic Rocks and PGE-Cu-Ni Sulfide Deposits of the Noril'sk Province, Polar Siberia. Field Trip Guidebook. Proceedings of the 12th International Platinum Symposium (July 31 - August 7, 2014). IGG UB RAS, Ekaterinburg, 80 p. http://dx.doi.org/10.13140/RG.2.1.1649.8009.

Sobolev A.V., Sobolev S.V., Kuzmin D.V., Malitch K.N., Petrunin A.G., 2009. Siberian Meimechites: Origin and Relation to Flood Basalts and Kimberlites. Russian Geology and Geophysics 50 (12), 999-1033. https://doi.org/10.1016/j. rgg.2009.11.002.

Spiridonov E.M., Kulagov E.A., Serova A.A., Kulikova I.M., Korotaeva N.N., Sereda E.V., Tushentsova I.N., Belyakov S.N., Zhukov N.N., 2015. Genetic Pd, Pt, Au, Ag, and Rh Mineralogy in Noril'sk Sulfide Ores. Geology of Ore Deposits 57, 402432. https://doi.org/10.1134/S1075701515050062.

Starostin V.I., Sorohtin O.G., 2011. A New Glance at the Origin of Deposits of the Norilsk Type. Moscow University Geology Bulletin 2, 3-12 (in Russian) [Старостин В.И., Сорохтин О.Г. Новые основания для оценки происхождения месторождений норильского типа // Вестник
Московского университета. Серия 4. Геология. 2011. № 2. C. 3-12].

Tolstykh N., Shvedov G., Polonyankin A., Korolyuk V., 2020. Geochemical Features and Mineral Associations of Differentiated Rocks of the Norilsk 1 Intrusion. Minerals 10 (8), 688. https://doi.org/10.3390/min10080688.

Turovtsev D.M., 2002. Contact Metamorphism of the Norilsk Intrusions. Nauchny Mir, Moscow, 293 p. (in Russian) [Туровцев Д.М. Контактовый метаморфизм Норильских интрузий. М.: Научный мир, 2002. 293 с.].

Urvantsev N.N., 1923. A Brief Account of the Work of the Norilsk Geological Party over the Period from Summer 1921 to Autumn 1922. Bulletin of the Siberian Section of the Geological Committee 3 (3), 83-84 (in Russian) [Урванцев Н.Н. Краткий отчет о работах Норильской горной партии за период с лета 1921 г. по осень 1922 г. // Известия Сибирского отдела Геологического комитета. 1923. T. 3. № 3. C. 83-84].

Urvantsev N.N., 1927. Copper-nickel exploration of Norilsk in the Lower Reaches of the Yenissei River. Bulletin of the Geological Committee 44 (2), 190-191 (in Russian) [Урванцев Н.Н. Разведка медно-никелевого месторождения Норильска в низовьях р. Енисея // Известия Геологического комитета. 1927. Т. 44. № 2. С. 190-191].

Walker R.J., Morgan J.W., Horan M.F., Czamanske G.K., Krogstad E.J., Fedorenko V.A., Kunilov V.E., 1994. Re-Os Isotopic Evidence for an Enriched-Mantle Source for the Noril'skType, Ore-Bearing Intrusions, Siberia. Geochimica et Cosmochimica Acta 58 (19), 4179-4197. https://doi.org/10.1016/ 0016-7037(94)90272-0.

Wooden J.L., Czamanske G.K., Bouse R.M., Likhachev A.P., Kunilov V.E., Lyul'ko V., 1992. Pb Isotope Data Indicate a Complex, Mantle Origin for the Noril'sk-Talnakh Ores, Siberia. Economic Geology 87 (4), 1153-1165. https://doi.org/10. 2113/gsecongeo.87.4.1153.

Wooden J.L., Czamanske G.K., Fedorenko V.A., Arndt N.T., Chauvel C., Bouse R.M., King B.-S.W., Knight R.J., Siems D.F., 1993. Isotopic and Trace-Element Constraints on Mantle and Crustal Contributions to Siberian Continental Flood Basalts, Noril'sk Area, Siberia. Geochimica et Cosmochimica Acta 57 (15), 3677-3704. https://doi.org/10.1016/00167037(93)90149-Q.

Woodland S.J., Pearson D.G., Thirlwall M.F., 2002. A Platinum Group Element and Re-Os Isotope Investigation of Siderophile Element Recycling in Subduction Zones: Comparison of Grenada, Lesser Antilles Arc, and the Izu-Bonin Arc. Journal of Petrology 43 (1), 171-198. https: //doi.org/ 10.1093/petrology/43.1.171.

Zolotukhin V.V., Ryabov V.V., Vasilyev Yu.R., Shatkov V.A., Sobolev V.S., 1975. Petrology of the Talnakh Ore-Bearing Differentiated Trap Intrusion. Nauka, Novosibirsk, 432 p. (in Russian) [Золотухин В.В., Рябов В.В., Васильев Ю.Р., Шатков B.А., Соболев В.С. Петрология Талнахской рудоносной дифференцированной трапповой интрузии. Новосибирск: Наука, 1975. 432 с.]. 